\title{
3D SCANNING METHODOLOGY: BELL TOWER OF SANTA MARÍA DE DAROCA'S CHURCH (SPAIN)
}

\author{
C. López González ${ }^{1, *}$, P. Germes Valls ${ }^{2}$ \\ ${ }^{1}$ Research Centre PEGASO, Universitat Politècnica de València, Valencia, Spain - mlopezg@ega.upv.es \\ ${ }^{2}$ Universitat Politècnica de València, Valencia, Spain - pabgerva@alumni.upv.es
}

Commission II - WG II/8

KEY WORDS: 3D scanning of towers; Bell tower of the Church of the Sagrados Corporales; Vaults by approach of brick courses; Aragonese Mudejar.

\begin{abstract}
:
Santa María's Church finds its origins in a medieval mosque located in the city of Daroca, whose historical centre was declared a Historic-Artistic Complex (1968) and, at present, it is considered an "Asset of Cultural Interest". The bell tower is the only remnant of the Islamic mosque that is preserved. In the 14th century, the Mudejar tower was covered with ashlar masonry and increased in height. The conjunction of successive stages of construction, with the different construction systems and materials used in each period, as well as the different architectural styles that can be contemplated in this tower, convert it into a unique and complex exemplary work. However, despite being a bell tower of great heritage value, there is no rigorous planimetry available of any kind allowing its in-depth study. Due to its complexity and diversity of materials, it has required the use of the 3D laser scanning technology. The shortage of space and light made it necessary to carefully plan the sequential stationing process and the results have been very satisfactory. The scanning has allowed detection of the tower's inclination with great precision and has facilitated the visualization of the meeting point of both Arabesque and Christian remnants. It has also been proven that the bell tower's inclination is not uniform throughout the height of the closing wall, but is slightly straightened from the Christian period. This communication describes the process followed to perform the scanning and subsequent manipulation of point clouds, presenting the results obtained.
\end{abstract}

\section{INTRODUCTION}

\subsection{Background}

The architectural ensemble of Santa María finds its origins in a medieval mosque located in the city of Daroca, whose historical centre was declared an Historic-Artistic Complex (1968) and is currently considered an "Asset of Cultural Interest". Construction of the church began in 1130 following a Romanesque architectural style and later on, at the end of the 16th century, underwent a significant intervention doubling the surface of the temple and reorienting it, becoming a so-called hall-church (Figure 1).

From the Romanesque church, just a few elements remain: the semi-circular apse oriented to the East and converted after the intervention of the 17th century into a side chapel where the Sagrados Corporales are preserved; the walls enclosing a chapel situated to the North of the apse; and a wall with a window to the South. These vestiges and the graphic analysis performed (López, Germes, 2019) confirm the existence of a triabsidal sanctuary. This typology was deeply rooted in the peninsular territory, finding in the Church of San Miguel in Daroca another preserved example of similar characteristics built around the same dates.

From the Gothic church, it is still possible to admire the splendid façade del Perdón and some of its side walls. Between 1357 and 1359, part of the church was covered with ceramic tiles from Teruel and subsequently a high choir was built.
According to a manuscript from the Parochial Archive of Daroca (Pano, 1989, p. 512), the choir connecting the church to the bell tower at the time was situated at the belfry level.

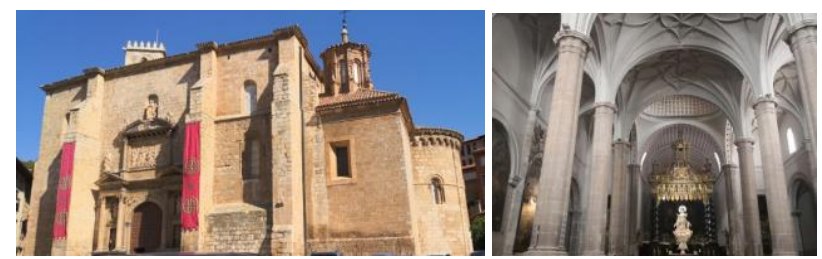

Figure 1. Exterior and interior of Santa María's Church. Image by the authors.

The Gothic church had three naves, the central one being of greater height and having two access doors in the main and the Southern façades (Rodríguez, 1877).

The bell tower is the only element of the church where we find a confluence of vestiges from all the constructive stages that this architectural ensemble has gone through. In the 14th century, the Mudejar tower was covered with ashlars and in 1441 it was raised in height (Pano, 1987). The conjunction of successive building stages, with the different construction systems and materials used in each period, as well as the different architectural styles that can be contemplated in this tower, make of it a unique and complex exemplary work. However, in spite of being a bell tower of great patrimonial value, there is no rigorous planimetry of any kind allowing its in-depth study (Figure 2).

\footnotetext{
* Corresponding author
} 


\subsection{Objectives}

The research work carried out has been aimed at the constructive and morphological analysis of the bell tower of Santa María de Daroca's church with the objective of establishing the constructive evolution and document the current state of this unique element. This main objective can be subdivided into three specific objectives:

1. To study the structures supporting the bell tower and its interior staircase, establishing comparisons with others of similar characteristics constructed in the same period.

2. To analyse the possible deviations and buckling that these elements may have been developing throughout their lifetime.

3. Additionally, a third specific objective necessary for the achievement of the previous two had to be considered. That is, the elaboration of a rigorous survey plan of this unique tower allowing to establish reliable measurements of small magnitudes.
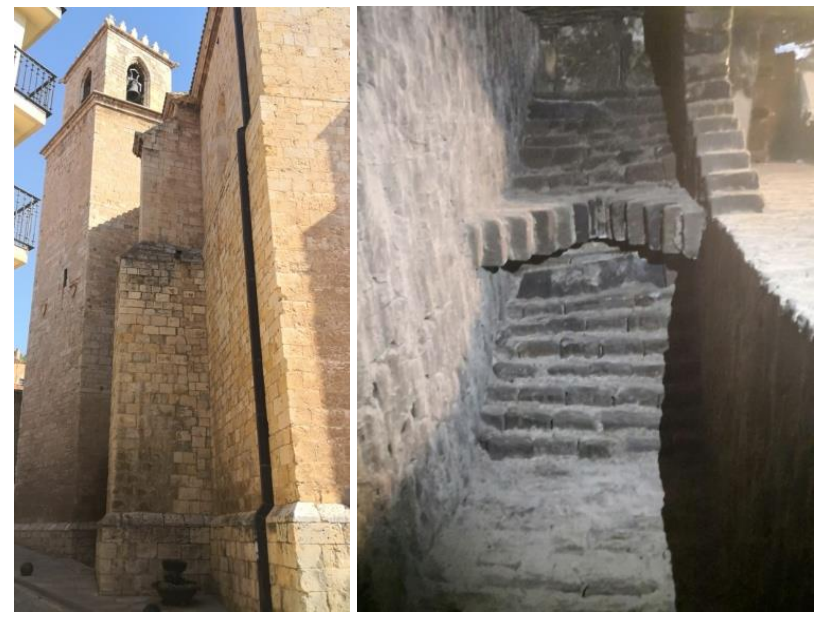

Figure 2. Exterior and interior of the bell tower.

Given the complexity and diversity of materials and shapes, the only means by which reliable data could be obtained was through the use of terrestrial laser scanning (TLS). This is a new technology for the collection of metric and geometric data that has been used since 2001 (Rodríguez, Chamizo, Afana, Solé and Cantón, 2012). It has been extensively applied to many areas such as archaeology, geomorphology and architecture among others, but it is perhaps in the latter where it has been most frequently used since it has provided an answer to the construction data collection whose complexity does not allow the use of traditional methods.

This is the case of the bell tower of Santa María's church, where the development of irregular surfaces, arches of different shapes, spaces of difficult access and structural deformations, make the lifting of planes by traditional methods based on the use of laser distance meters and topographic stations unapproachable. On the contrary, the laser scanner carries out a sweep of points on the surfaces on which the laser beam strikes, creating a cloud of points that perfectly reproduces the substrate to be determined. "The cloud feature is not only due to the large number of points obtained but also to the fact that these points generate a nebula surrounding the object scanned" (Ramos, Marchamalo, Rejas and Martínez, 2015).

\section{METHODOLOGICAL PROCESS}

\subsection{TSL required features}

The complexity of the morphological characteristics of Santa María's bell tower make it necessary to conduct an analysis prior to scanning in order to determine the most suitable equipment to obtain the best possible results.

The tower is a high-rise architectural element: 33.51 meters from the floor inside the basilica to the rooftop at the bells area, where the battlements are located. Including this latter constructive element, the bell tower reaches a total height of 34.63 meters.

Inside the tower there are light sources and electrical outlets only on the ground floor level. The rest is lighted solely through the scarce and small windows distributed along the façade. In consequence, almost all of the scans had to be conducted in very poor or even non-existent lighting conditions.
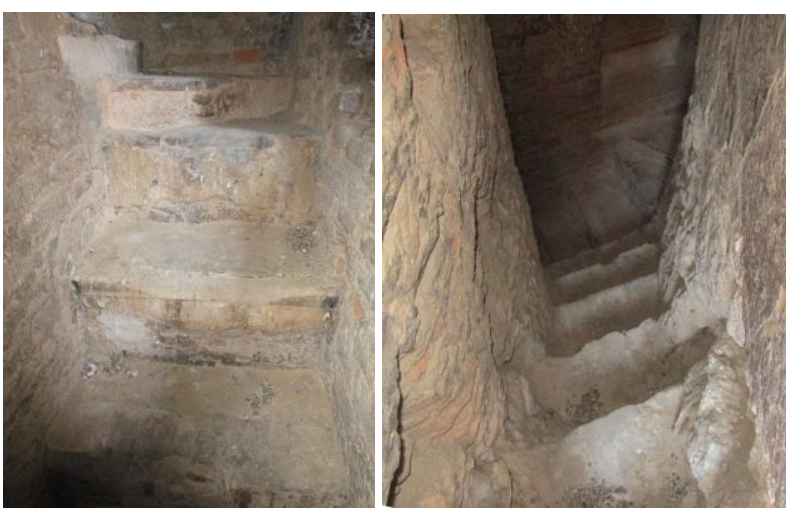

Figure 3. Brick square box staircase with stone screed in the access to the space immediately bellow the cover of the temple.

On the other hand, the narrowness of the climbing stairs $(69.5$ centimetres width on average), with worn rungs and uneven steps and risers, greatly hindered the access and placement of the scanning device. All over, we must add the irregularity of the surfaces delimiting the staircase, as well as the diversity of shapes of the supporting arches, which prevented the use of points and surfaces as a reference to subsequently match the different point clouds (Figure 3 ).

It is, therefore, an architectural element of difficult access, poor lighting, lack of electrical outlets and irregular surfaces, in addition to the substantial amounts of dirt and dust layers.

A scanner allowing overcoming all these difficulties was needed. The Faro 3D laser scanner, Focus 3D-130 model, obtained by the research group through a competitive call launched using FEDER funds, was employed. The characteristics of this model were appropriate to the needs of the work: the fundamental feature that made it ideal is the small size and low weight of the device, of dimensions 24 x 20 $\mathrm{x} 10 \mathrm{~cm}$. and a weight of $5.2 \mathrm{~kg}$ which facilitated its manageability in the reduced space inside the tower. Additionally, it has an integrated lithium-ion battery with a four-hour runtime, which ensured its use without the need to connect it to the electrical power during a workday, as required for the scanning of the bell tower. The scanner has a systematic distance error of $2 \mathrm{~mm}$ at 25 meters, which was acceptable for the purpose of the study. 
This scanner allows scanning at a speed between 122,000 and 976,000 points per second, so the time of each scan is not high. The scans conducted in the bell tower were carried out at a speed of 488,000 points/sec. which translates into a duration of approximately 8 minutes per scan. The device also includes an integrated 70 megapixels camera with parallax-free colour overlay so the point clouds obtained have a photographic realism that greatly facilitates the understanding of the final point cloud. The camera has HDR (High Dynamic Range), that is, it sheds light over poorly lit areas so that it adds more "dynamic range" to the photograph, increasing the number of shades. This feature was also of relevance given the poor lighting inside the tower.

Another remarkable advantage in this case was that the scan's final output format was an FLS format file, which allows reading by all the processing software.

\subsection{Prior programming of the scans}

The morphology of the tower itself posed an initial problem of wingspan due to the reduced dimensions of the space, the irregularity of the enclosing surfaces and steps; the poor lighting, which in many cases was non-existent; the existence of sustaining brick arches; the diversity of constructive systems used: multiple types of arches, vaults of different designs and materials; and, finally, the difficult access to the tower's rooftop through a narrow metal spiral staircase.

Under these circumstances, it was necessary to carefully plan the sequential stationing process, which was divided into two phases: the first phase going from the ground floor access to the height reached by the square box staircase, and the second one carried out in a downward direction beginning with the cover and belfry to reach the point of meeting with the previous phase. This unique approach was conditioned by the area's adverse climate, where there are intense snowfalls and blizzards. The device used works correctly between $5^{\circ}$ and $40^{\circ} \mathrm{C}$, not being advisable to its use it in temperatures out of this range. Thus, it was necessary to perform the external scanning in the morning, during the hours when the temperature was higher to avoid damage to the scanner. Also, the scanning of the cover was conducted at the time of highest natural daylight intensity. To this circumstance must be added the need to use the scanner during this first 4 hours in this area of the tower lacking electrical outlets.

In principle, no referential spheres were used since, from the beginning of the project, it was assumed that the point clouds manipulation could be done manually using any software. However, given the narrow spiral staircase, their use was necessary because there were no unique references such as points, corners, edges or flat surfaces belonging to the constructive elements of the tower itself.

Adding to the challenge was the irregularity of the step's horizontal surface, which complicated the accurate placing of the scanning device. Therefore, in many cases, the low visibility between one scan and the next forced the addition of intermediate scans which had not been previously planned.

The final result, therefore, was the completion of 27 internal and 13 external scans.

\subsection{Scans' processing}

To carry out the processing of the scans and to be able to transform them into a single file that could be easily handled, we used the FARO SCENE software. For the registration of point clouds, the automatic system used by this program was initially employed, looking for similarities between planes and points among the different scans in order to match them. The automatic registration worked without errors on the outside scans of the tower by having enough references, both of points and of flat surfaces and also by having performed the scans with plenty of light. However, with the tower's internal scans we faced two problems: in some instances, the software did not find references that would allow the matching and in others it used the wrong reference generating an erroneous set. In the face of these problems, it was decided to carry out the registration manually. Inside the tower, existing nails or stains on the brick of the walls were used as references. No targets were used due to the impossibility of adhering them to the walls due to the large amount of dust accumulated. To facilitate the search of the planes and points, it was decided to use black and white scans, marking only the points. In this way, it was achieved that the poor interior lighting did not affect the results (Figure 4).

The registration was done in two stages: the first one corresponding to the first group of scans (square box staircase) and the second one corresponding to that made from the top of the tower to meet the last scan of the previous group. The first stage's registration was complex due to the difficulty that the Scene software poses when recognizing points over irregular and dirty surfaces. The second stage's registration was easier due to the planned strategic location of spheres as reference points. Therefore, obtaining the final point cloud was a very laborious process where many of the erroneous solutions that the program facilitated had to be dismissed. The completion of 27 scans inside the tower greatly lengthened the process.

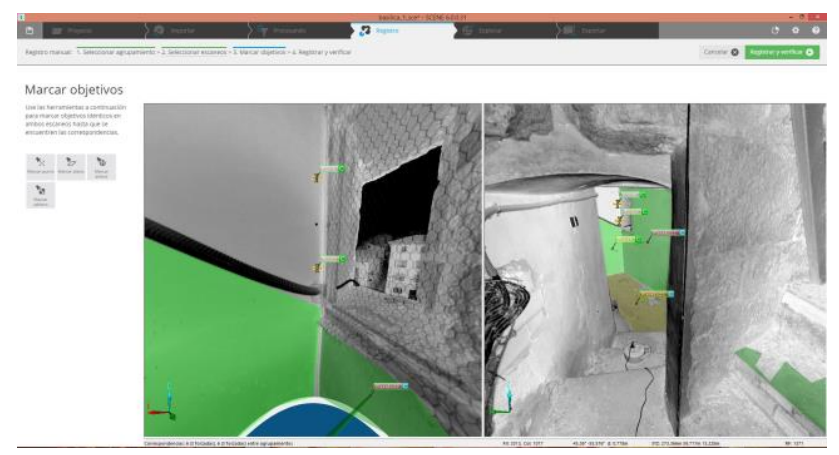

Figure 4. Manual registration by the Scene software.

Once a registration of the tower was obtained, it was joined to the rest of the basilica, allowing the tower to be perfectly located in relation to the temple without error. This action was performed exactly in the same manner both with the exterior of the tower and the exterior of the basilica.

Once all the registration groups were joined together, the resulting cloud was coloured, linking the result to the images made by the scanner. In this way, the coloured point cloud was obtained.

Finally, in order to obtain a single file, the registrations were verified and the bonding and cleaning up process took place. The Scene software itself performs automatic colour adjustments and stabilizes the different registrations by generating the point cloud that is subsequently exported to other programs to be used in a .dwg file format. 
The Scene program displays an interesting feature allowing generating sections over the point cloud. For this, virtual cubes are created on the final point cloud in such a way that it is possible to subsequently erase all the points inside (or outside) the cube. This strategy permits to create sections where, in addition to the sectioned areas, the projection points are also displayed. Depending on the width of the bounding cube we obtain more or less additional information. In the case of making a thin slice, only the sectioned solids are displayed. This tool has been used to obtain bell tower section cuts allowing detecting the inclination of each stretch or constructive stage with respect to the vertical. (Figure 5).

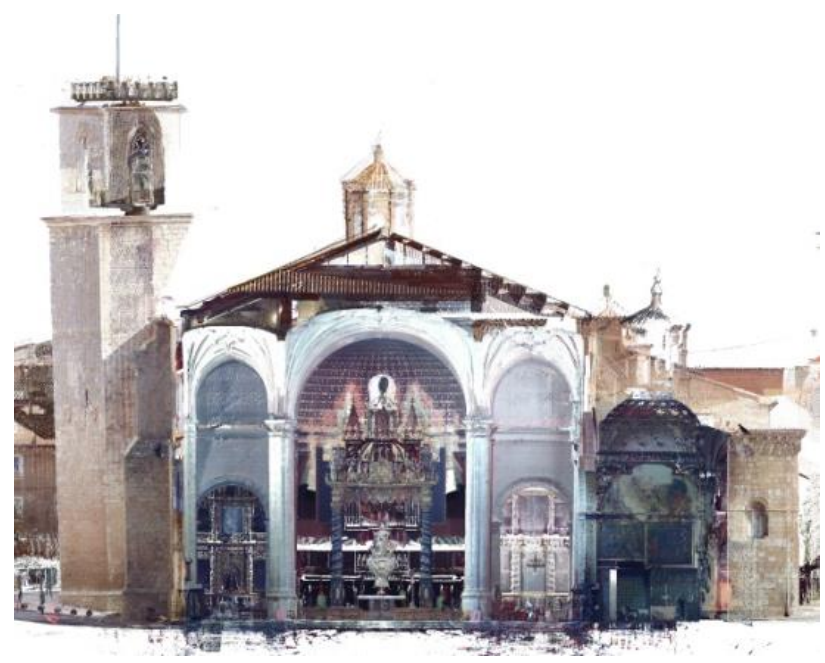

Figure 5. Orthophoto of the tower elevation.

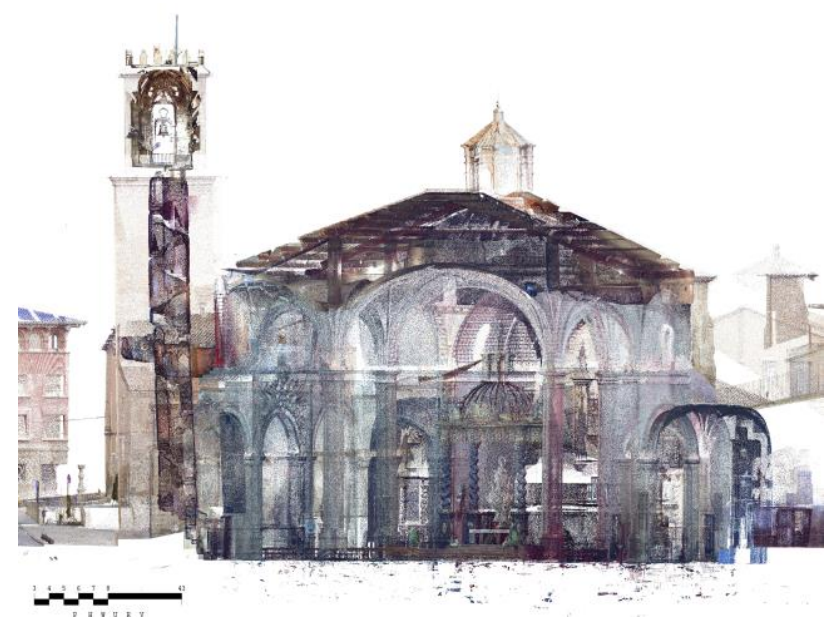

Figure 6. Cross-sectional scale orthophoto of the tower.

All these views in orthogonal projection (floors, vertical sections and elevations) can be converted into JPG format images by performing scaled orthophotos (Figure 6).

To obtain the dimensional data of height, inclinations, widths, depths, the Revit software has been used. This program supports the insertion of point clouds using the ".rcp" format files. Since these files are not directly generated by the Scene software, the option of making an ".e57" format file was raised. However, these files have an excessive large size. To solve this problem and obtain the ".rcp" file, the Recap program was used. This program is also used for the registration of point clouds and their subsequent processing. Thus, we inserted the ".e57" format file and exported it in ".rcp" format to Revit.
Once inserted in Revit, the cloud is adjusted and oriented vertically and horizontally until the scan is adapted to the $\mathrm{X}, \mathrm{Y}$, $\mathrm{Z}$ coordinate system (Figure 7). Subsequently, the levels were located in the selected areas: interior floor, exterior floor, bell tower's rooftop and bell tower intermediate space, thus obtaining the heights and widths of walls and staircase. Also, the inclinations and heights were obtained from the section planes arranged at different depths. In so doing it was possible to obtain dimensions without having to make a drawing.

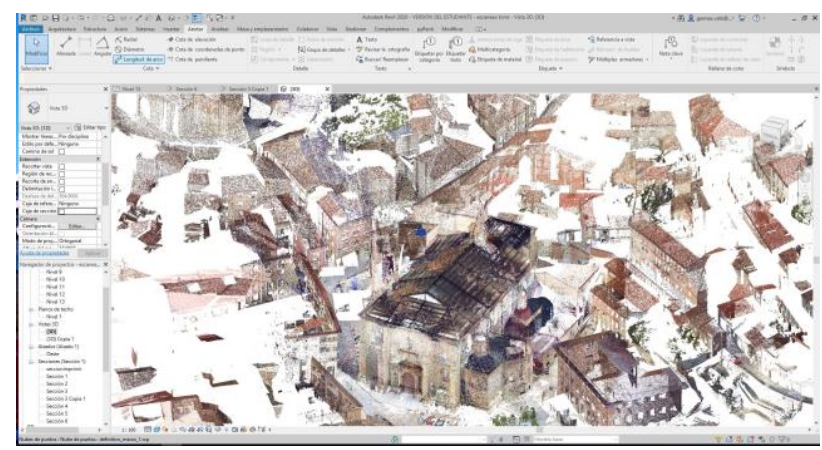

Figure 7. Point cloud in Revit.

\section{RESULTS}

\subsection{Results related to the dimensions of the tower}

The main result of the scan has been obtaining the dimensions related to the three sections integrating the tower: The lower section, whose staircase is of square plan shape; the intermediate section, with a circular spiral staircase with a first stretch of brick and finished in stone; and the belfry.

These measurements have been metrologically analysed with the Arabic metric system based on the rassasi elbow $(58.93 \mathrm{~cm})$ and the mamuni elbow $(47.14 \mathrm{~cm})$ in order to verify which sections could have been constructed in the Arabic or Mudejar period. The use of this system was noticed in Córdoba and rigorously studied by Félix Hernández (Hernández, 1962). Additionally, to verify those sections that could have been built in the Christian era, the analysis was performed using the Aragonese span $(19.3 \mathrm{~cm}$.) as a measuring unit.

The results obtained are shown in the following table:

\begin{tabular}{|l|l|l|l|l|}
\hline Widths & Meters & $\begin{array}{l}\text { Rassasi } \\
\text { elbow }\end{array}$ & $\begin{array}{l}\text { Mamuni } \\
\text { elbow }\end{array}$ & $\begin{array}{l}\text { Aragonese } \\
\text { span }\end{array}$ \\
\hline Square brick box staircase \\
\hline Walls & 1.160 & 2 & 2.5 & 6 \\
\hline Stairs & 0.695 & 1.8 & 1.5 & 3.6 \\
\hline Spiral brick staircase \\
\hline Walls & 2.420 & 0.4 & 5.1 & 12.5 \\
\hline Stairs & 0.994 & 1.7 & 2 & 5.2 \\
\hline Spiral stone staircase & 2.420 & 0.4 & 5.1 & 12.5 \\
\hline Walls & 0.951 & 1.6 & 2 & 5 \\
\hline Stairs & \multicolumn{5}{|l}{} \\
\hline
\end{tabular}

For the analysis, whole numbers or multiples or submultiples were considered (García, Ruiz, 2010). After verifying the agreement with the measures analysed, we considered that the equivalence of the brick sections with the mamuni elbow and of the stone sections with the Aragonese span was acceptable. 

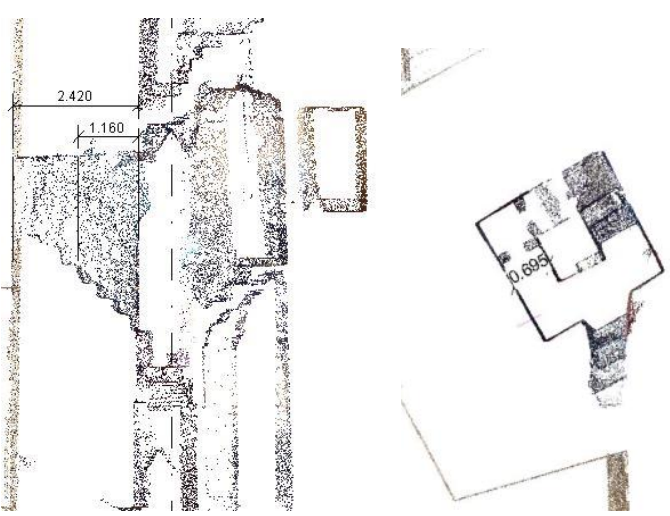

Figure 8. Measurement over the point cloud of the wall thickness and the width of the staircase at the meeting point of the two construction stages.

In addition to the dimensional data, the scans have facilitated the visualization of the meeting point of the tower's different construction stages, taking into account the materials used, the morphology of the spaces and the structural system employed (Figure 8).

Furthermore, it has been found that there is greater dimensional irregularity of the steps in the square staircase section than in the circular section, probably due to poor definition and greater surface wear due to longer use. Moreover, in the scans it could be verified that the Arab windows were larger, being later reduced in size when the tower was lined with ashlars in Christian times.

\subsection{Results related to the inclination of the tower}

Looking at the tower from the surroundings, one may observe a slight inclination towards the West, which has never been represented in the scarce plans that have been made of it, not even in those produced in 1992 for the intervention of the church's cover. The scanning has allowed detecting the tower's tilt with great accuracy since the device ranging error is \pm 2 $\mathrm{mm}$, according to the technical specifications of the Faro Focus3D x 130 laser scanner.

When analysing the different sections, it is observed that the inside of the tower has two inclination values: In the square base staircase section, there is an inclination of $2.32^{\circ}$ reaching 47.6 centimetres of difference from the vertical. In the spiral staircase section, the inclination switches to $11^{\prime} 14^{\circ}$ by getting slightly straighten, reaching a total difference with respect to the vertical of 75.6 centimetres (considering the vertical taken from the lower interior point of the West wall).

On the outside, the tower has an inclination of $0.4^{\circ}$ degrees up to the belfry, resulting in about $30 \mathrm{~cm}$ of difference with respect to the vertical obtained from the lower point of the exterior of the West wall. The upper section housing the bells does not present any inclination. Therefore, the inclination is not uniform throughout the height of the closing wall of the bell tower, but it is rather slightly straightened, which could be due to the fact that, at the time of increasing the height in the 14th century, the Arab tower was already inclined and an attempt to rectify the tilt was made.

It has also been verified that the dividing wall of the basilica and the bell tower is inclined as well, confirming a ground settling taking place in the area (Figure 9).

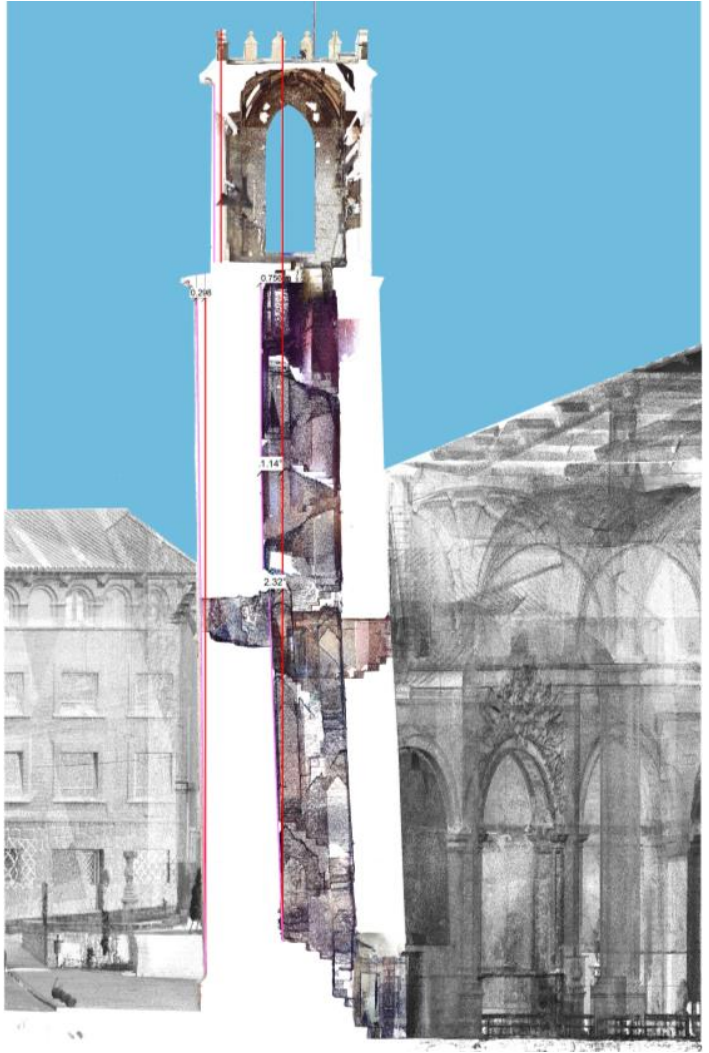

Figure 9. Inside and outside tilt of the bell tower with respect to the vertical.

\subsection{Results related to the structure of the tower}

The structural system that supports the inner staircase varies as it rises. In the lower section occupied by the square box staircase, the walls are built with solid brick up to a height of 15.11 meters and have a thickness of 1.16 meters, being covered with stone ashlars reaching a total thickness of 2.42 meters. The arrangement of arches and vaults supporting the stairs' structure are also built with solid brick using a simple technique that does not require auxiliary centring. It is a type of vault known as corbel vault or by approach of brick courses.

It consists of arranging successive rows of bricks, so that each course is flown over the lower course starting from two parallel walls, until the two cantilever arms meet at the top.

Due to their constructive ease, speed of execution and economy of means, they have been used from ancient times to the present day, usually in vernacular architecture such as the vaults covering auxiliary constructions such as water tanks and catxirulos, or small constructions used as shelters for shepherds and farmers. We find examples throughout the Iberian Peninsula, especially those executed with dry-stone walls from the East of the peninsula (Fornieles, López, 2019).

The vaults built without centring were widely used in Islamic architecture. These vaults were improved by slapping the brick with the first course inclined forming a complete arch. In this way, the inclination provides the necessary support for the next course, allowing covering spaces of rectangular, square or circular plan. This way of building finds its origin in the Mesopotamian tradition and Iran, where it reached high levels of perfection under the Sassanids (Lewcock, 1985). However, for narrow spaces whose distance between walls is small, the technique of the corbel vault was used. 


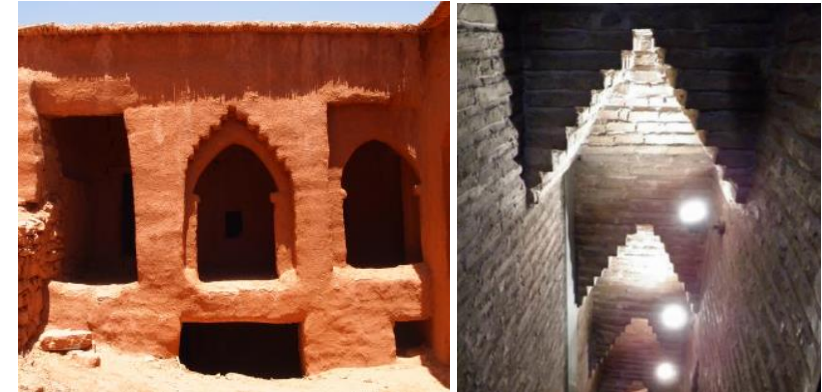

Figure 10. Corbel vaults of in Ait Ben Haddou (Morocco) and the Torre del Salvador (Teruel).

This construction technique was widely used by the Arabs. In Al-Andalus, it was used to cover small gaps, such as in the side arches of San Esteban's door of the Aljama Mosque of Córdoba (s. IX). It can also be observed in the main access door to the Qadima Alcazaba (s. XI) (Hernán Román's door). Antonio Almagro has studied magnificent examples in the area of the "Middle Mark" as the vault of the postern gate of the Arab castle of Gormaz (Soria) (s IX-X) or the Casares tower in Riba de Saélices (Guadalajara) (Almagro, 2001, p. 155). In Aragon, it was a system extensively used in Arab and Mudejar architecture, as seen in the Torre del Andador in Albarracín (Teruel) and in the vaults covering the staircase and the perimeter aisles of the towers of San Martín and del Salvador in Teruel (s. XIV).

The structural system of the lower section of the Santa Maria's tower is simpler than in the Turolense towers. It is composed of the four perimeter walls housing inside the four-section staircase that rests on the walls and on a central abutment. All built in brick. Each section of the staircase rests on a false vault formed by approximation of brick courses perpendicular to the walls that serves to form the inclined surface on which the three rungs of each section rest. This false corbel vault rests its sides on the perimeter wall and on the central abutment. Its ends rest on arches formed by springers located in the corners of the abutment. They are perpendicular to the closing wall in such a way that from each corner two arches arise perpendicular to each other. These are bracing arches of the perimeter walls. Over these arches and over the two tower's closing walls, rest the vaults of the landings. The false vaults of the staircase sections and the arches on which it rests and that serve as bracing of the perimeter walls, are formed by 7 courses acquiring the shape of an equilateral triangle. It is a structure apparently complex but of very simple resolution (Figure 11).

This typology continues to a height of $15.11 \mathrm{~m}$, where the inner space transforms its square plan into a circular one and the box staircase becomes a spiral staircase with a central abutment. The construction of walls, steps and abutment continues to be of solid brick. The vault supporting the steps is also a vault by approach of courses as in the square box staircase, but in this case the overhangs of each course increase as it moves away from the central abutment and approaches the perimeter wall. The courses are made out by bricks laid in a bond pattern or in a stretcher pattern constituting a beautiful example of a corbel vault (Figures 12 and 13).

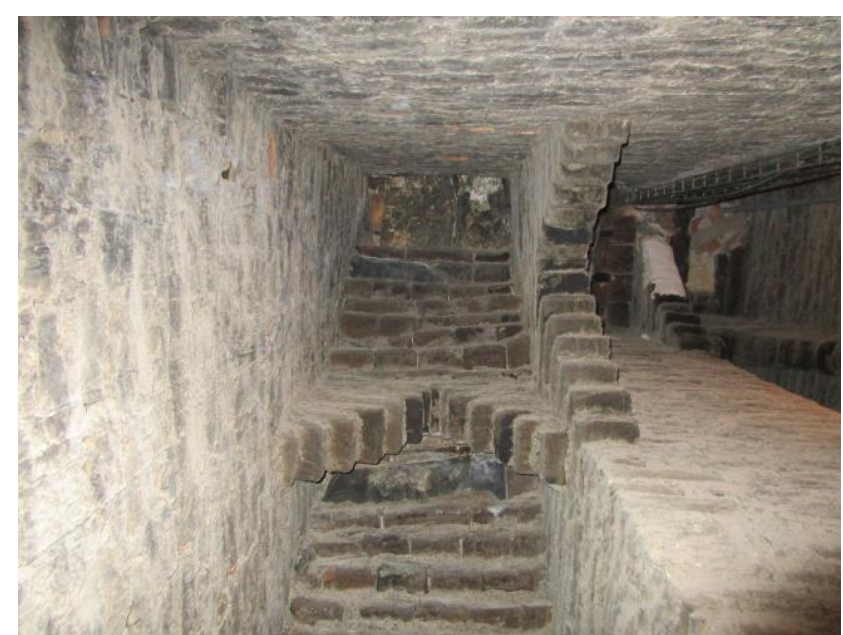

Figure 11. Corbel arches for bracing the walls and corbel vault for supporting the steps and the landing.

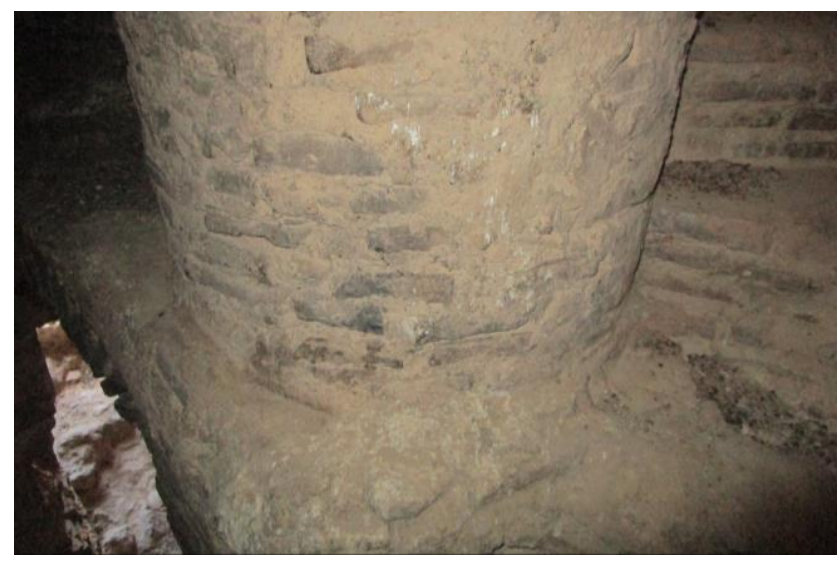

Figure 12. Point at which the central abutment becomes circular.

The courses are bonded with plaster, this being a fast setting material that facilitates the construction process.

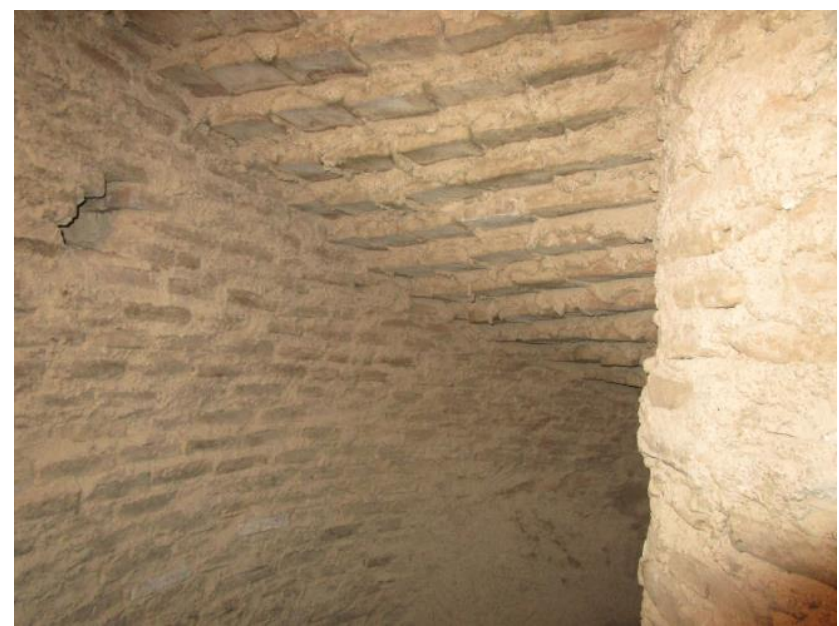

Figure 13. Point at which the central abutment becomes circular and a corbel vault in the spiral staircase. 


\section{CONCLUSIONS}

The 3D scanning-based methodology used has allowed a rigorous survey of a complex bell tower that would have not been possible to achieve by other means or techniques. Likewise, it has been possible to accurately measure the deformations suffered over time, verifying that the deviations differ in each construction stage.

Additionally, we have been able to precisely determine the constructive evolution from its Arab origin to the present day through the rigorous and precise measurement taken by means of the point cloud and its implementation in Revit, verifying that the dimensions of the lower section of the tower fit the mamuni elbow and the upper section, built in stone, fit the Aragonese span. Likewise, the thicknesses of the walls and the heights of the different construction stages have been measured, verifying that the first one is $15.11 \mathrm{~m}$. high, that is, 32 exact elbows, which leads one to think that this part belonged to the ancient Islamic mosque's minaret on which the church sits. Similarly, the thickness of slabs and vaults of the staircase has been accurately measured, corroborating that in the lower section built in brick they are thinner and uneven, while in the Christian section they are greater and uniform.

\section{ACKNOWLEDGEMENTS}

We thank Mr. Sergio Pérez, priest of the Church of Santa María and the Religiosas Auxiliadoras de Cristo Sacerdote for the facilities provided to access the temple and the bell tower. We also thank Mr. Pascual Sánchez Domingo, responsible for the archive, for his full disposition and assistance in the search for documentation.

\section{REFERENCES}

Almagro Gorbea, A., 2001: Un aspecto constructivo de las bóvedas en al-Andalus. Al-Qantara revista de estudios árabes XXII (1) 147-170

García Ortega, A.J., Ruiz de la Rosa, J.A., 2010: Diseño estructural en el primer gótico andaluz (II) Maestros y medidas. Ega Revista de Expresión Gráfica en la Arquitectura 15, 46-53

Hernández, F., 1962: El codo en la historia árabe de la mezquita mayor de Córdoba. Contribución al estudio del monumento. AlMulk Anuario de estudios arabistas 2, 44-52

Lewcock, R., 1985: Materiales y técnicas. In La arquitectura del mundo islámico. Alianza editorial, Madrid. 129-142

López González, C., Germes Valls, P., 2019: Projective analysis of the church of Santa María de Daroca. The architecture speaks through the drawing. In Reflections the art of drawing/The drawing of art. Gaugeni Editore, Roma 1655-1662

Fornieles López, J., López González, C., 2019: Analysis construction of vaults with dry stone. In Research in building engineering Universitat Politècnica de València, 244-253

Ramos, L., Marchamalo, M., Rejas, J.G., Martínez, R., 2015: Aplicación del láser escáner terrestre (TSL) a la modelización de las estructuras: precisión, exactitud y diseño de la adquisición de datos en casos reales. Informes de la construcción 67 (538): e074, doi: dx.doi.org/10.3989/ic.13.103
Pano Gracia, J. L., 1987: Sobre la fábrica y capitulación de la iglesia colegial de Daroca. Artigrama 4, 91-114

Pano Gracia J.L., 1989: La portada del Perdón de la iglesia Colegial de Daroca: estado de la cuestión. Aragón en la Edad Media, VIII. Homenaje al Profesor Emérito Antonio Ubieto Arteta, 511-521.

Rodriguez-Caballero, E., Chamizo, S., Afana, A., Solé-Benet, A., Cantón, Y., 2012: Automatic digital terrain model extraction from terrestrial laser scanner data (Espada). In Avances de la Geomorfología en España. Universidad de Cantabria. 263-266 Rodríguez y Martel, J. A., 1877: Antigüedad célebre de la santa iglesia colegial de Santa María la Mayor de Daroca..., año 1675, Imprenta de T. Fortanet, Madrid, 242-248 